\title{
O homem transbordante nietzschiano e a perspectiva transpessoal
}

\author{
El hombre trascendente nietzscheano y la perspectiva transpersonal \\ The transcendent nietzschean man and the transpersonal perspective \\ Jorge Miklos ${ }^{1}$ \\ Renata Bastos Carneiro da Cunha ${ }^{2}$
}

\begin{abstract}
Resumo
O presente artigo estabelece relações entre a expressão nietzschiana übermensch, do livro Assim falou Zaratustra e a perspectiva transpessoal, que tem como referência tanto a pessoa como o para além dela. Há aproximação de ideias sobre este homem e os pressupostos da perspectiva transpessoal, em suas disposições de abertura e de integração. Convida-se a pensar que a Perspectiva Transpessoal é capaz não só de oferecer caminhos, como também de ajudar a trilhá-los, tanto em direção à pessoa, como ao para além dela. Isso mostra-se viável diante de significativas sinalizações em relação ao potencial humano presentes na abordagem nietzschiana que conferem muito mais do que um simples aceno das possibilidades de alcance do ser humano, pois o colocam em uma condição que extrapola, vai além ou está acima dele mesmo. Utilizou-se do método de revisão bibliográfica e concluiu-se que tanto a perspectiva transpessoal, como a visão de homem nietzschiana, levam à necessidade desses vários homens (ou estados de consciência), serem vivenciados em estados variados, como o de morte, mutação ou transbordamento.
\end{abstract}

Palavras-chave: Übermensch. Homem. Transbordante. Transpessoal.

\begin{abstract}
The present article establishes relations between the Nietzschean expression $\ddot{0} b e r m e n s c h$, from the book Thus spoke Zarathustra and the transpersonal perspective, which has as reference both the person and the beyond. There is an approximation of ideas about this man and the presuppositions of the transpersonal perspective, in his dispositions of openness and integration. One is tempted to think that the Transpersonal Perspective is capable not only of offering paths, but also of helping to tread them both towards the person and beyond. This is feasible in the face of significant signals in relation to the human potential present in the nietzschean approach that confer much more than a simple nod of the possibilities of reach of the human being, because they place him in a condition that extrapolates, goes beyond or is above him same. The method of bibliographical revision was used and it was concluded that both the transpersonal perspective and the nietzschean man's view lead to the necessity of these various men (or states of consciousness) to be experienced in varied states, such as death, mutation or overflow.
\end{abstract}

Keywords: Übermensch. Man Overflowing. Transpersonal.

\section{Resumen}

El presente artículo establece relaciones entre la expresión nietzschiana übermensch, del libro Así habló Zaratustra y la perspectiva transpersonal, que tiene como referencia tanto a la persona como al más allá

\footnotetext{
${ }^{1}$ Doutor em Comunicação pela PUC-SP. Professor Titular do Programa de Pós-Graduação em Comunicação e Cultura Midiática da Universidade Paulista (UNIP). e-mail: jorgemiklos@gmail.com.

${ }^{2}$ Mestra em Filosofia na Faculdade de São Bento (SP). e-mail: rebastoscunha@ gmail.com.
} 
de ella. Hay aproximación de ideas sobre este hombre y los presupuestos de la perspectiva transpersonal, en sus disposiciones de apertura e integración. Se invita a pensar que la Perspectiva Transpersonal es capaz no sólo de ofrecer caminos, sino también de ayudar a recorrerlos, tanto hacia la persona, como hacia fuera de ella. Esto se muestra viable ante significativas señales en relación al potencial humano presentes en el enfoque nietzscheano que confieren mucho más que un simple acento de las posibilidades de alcance del ser humano, pues lo colocan en una condición que extrapola, va más allá o está por encima de él incluso. Se utilizó el método de revisión bibliográfica y se concluyó que tanto la perspectiva transpersonal, como la visión del hombre nietzscheana, llevan a la necesidad de estos varios hombres (o estados de conciencia), ser vivenciados en estados variados, como el de muerte, o desbordamiento.

Palabras clave: Übermensch. Hombre Trascendente. Transpessoal.

\section{INTRODUÇÃ̃O}

escolha deste tema inspirou-se na expressão "homem transbordante"
presente no artigo de Rubem Alves, referente ao übermensch nietzschiano,
da obra Assim falou Zaratustra. Tal termo foi relacionado à perspectiva transpessoal. No transcorrer do estudo, constatou-se que o radical über tem como significado literal "acima de", sutilmente diferente de "para além", do radical trans, ou até mesmo da relação que se faz de super-homem com a palavra superação, ambas provindas de über.

Diante da "falta presente" no ser humano, ou necessidade de trabalho e conquista de outros em si mesmo, considerou-se a pertinência da perspectiva transpessoal em ofertar especial auxílio a esta possível aquisição. Por estar aberta e, em formação, também teria muito a ganhar com um pensador revolucionário e extremamente atual, no que diz respeito à indicação de transformação ou elevação do homem. Neste sentido, houve soma de perspectivas ricas e voltadas para um acréscimo no homem e no mundo em que vive, bem como possibilidade de agregar ambas as partes - pensamento nietzschiano e a perspectiva transpessoal -, sendo citadas suas aproximações.

A possibilidade do homem alcançar esse "além dele", independentemente das distâncias ou distinções teóricas dos termos em questão, é algo difícil e que exige boa dose de dedicação e paciência, qualidades que, cada vez mais, podem ser consideradas anti-modernas. A perspectiva transpessoal, em sua sabedoria vivencial, seguramente auxiliaria neste processo, por se predispor à integração, trabalhá-la, sendo esta mesma integração resultante ora de uma mutação ou morte, ora de uma forma mais suave e acolhedora.

Assim, o objetivo deste ensaio é apresentar as relações entre o "super-homem" nietzschiano e as forças da perspectiva transpessoal, aproximando, dessa forma, pensamentos que, juntos, oferecem contribuições para o campo desta que é considerada a atual força da, 
existindo nela ideias que podem ser relacionadas em uma mesma direção. Pretende-se ampliar o olhar proposto pela perspectiva transpessoal para o pensamento de Nietzsche, que oferece orientações para uma visão de transcendência do ser humano em direção a algo maior e acima dele mesmo. E em que medida a Perspectiva transpessoal pode auxiliar nesta possibilidade de elevação ou de alcance da condição "acima de", tal como indicado por Nietzsche por meio do termo übermensch?

O pensamento do "eterno retorno", presente de forma fundamental na obra Assim falou Zaratustra, de Nietzsche, nos apresenta uma concepção de humano que, em certa medida, dialoga com a ideia de espiral evolutiva presente no campo da perspectiva transpessoal. Vale dizer, há um percurso, uma ou várias formas que se unem em direção a um destino. E o homem, o ser humano, parece também ter essa rota dentro de si em direção a um sentido que, para Nietzsche, pode ser entendido como o de "super-homem", enquanto para a perspectiva transpessoal o foco é na pessoa, antes que se direcione para a trans-pessoa. Ambas as áreas, pode-se dizer, compactuam com a ideia de "ir além", através do homem e para além dele. Há a ideia de evolução e ela parece estar contida na possibilidade de elevação (ou evolução), não só pelo aumento de visão, como por maior abarcamento e compreensão holística da vida, de si, pressupondo-se aí, maior capacidade para dar, oferecer ou doar algo de si a um outro, mesmo que esse outro esteja em nós mesmos, propiciando-se assim, claramente, maior desenvolvimento da Espiritualidade ou dimensão espiritual.

Neste trabalho, no primeiro subitem investiga-se o livro Assim falou Zaratustra, que apresenta o termo übermensch, central neste tema, e, parafraseando Jung, como que a "constelálo". No segundo subitem, apresenta-se a perspectiva transpessoal e suas possibilidades de conexão com o título em questão. E o terceiro subitem é dedicado a estabelecer melhores relações entre estas possibilidades de troca, de somatória ou contribuição entre os dois sistemas de pensamento.

Bases teóricas, como conceitos, histórico e desenvolvimento foram usadas, assim como o livro do terceiro período de Nietzsche, Assim falou Zaratustra - um livro para todos e para ninguém. Por fim, deve-se citar também a inspiração inicial: o artigo de Rubem Alves, "O 'homem transbordante,".

\section{O "HOMEM TRANSBORDANTE" NIETZSCHIANO}




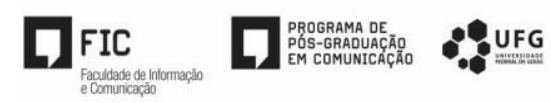

Escrever sobre o pensamento de Friedrich Nietzsche produz entusiasmo e ao mesmo tempo sensação de grande desafio, tal a peculiaridade formal do texto, que diz tanto ou mais do que o próprio conteúdo. Sua obra, além de extensa em termos quantitativos, consegue ser extremamente atual e, desde sua época, revolucionária. Pelo próprio uso de aforismos, comuns em seus textos, causa profundas reflexões, ao menos inspirando-as de forma intensa e contínua.

Nietzsche viveu de 15 de outubro de 1844 a 25 de agosto de 1900, mas continua, como já apontado, influenciando diversos movimentos, sendo um dos pensadores mais estudados em várias áreas do saber, dentre elas a própria filosofia.

Sua escrita peculiar, não somente na forma, convoca cada leitor atento (desatento também) a participar de seus pensamentos, mais do que comumente se consegue em outras leituras. E essa participação é propiciada tanto em direção às próprias colocações do autor, mas igualmente às do leitor, sendo talvez esta uma de suas grandes contribuições: conseguir causar movimentos inéditos tanto de raciocínio como de ideias, por meio de uma escrita pensante, movimentada e mobilizadora, igualmente propiciada em seus leitores. Não se trata de ser criativo ou original apenas, mesmo que conseguir isso já seja muita coisa, mas sim de inaugurar uma maneira de questionar e de refletir que bane a verdade única, uma ou diversas certezas, e também se trata de conseguir apresentar a saída como sendo uma não saída, se é que seja possível dizer assim. A escrita de Nietzsche cria um ambiente, contexto ou possibilidade de presente sem muito passado, para que possam, quiçá, existir movimentos mais livres, mais autênticos, mesmo quando em condições sem possibilidade para tals, já que há uma grande crítica estimulando uma mutação no próprio homem, para que possa alcançar sua denominação über (acima), presente na palavra alemã übermensch (acima do homem). Suas críticas são muito frequentes e em todas as direções, acima e abaixo também. Porém, afigura zoroástrica em eterno retorno, presente e falante para os que com ela se encontram, oferece condições reflexivas acerca da própria reflexão, contribuindo sobremaneira para as questões e quase nada para as definições.

Uma forma de discurso não previsível, poética e envolvente muitas vezes, provoca em muitos instantes a sensação de desconstrução, favorecendo um jeito livre, mais criador, para apresentar pensamentos e críticas possíveis de serem compreendidos e digamos assim, também aceitos. E as colocações deste autor entram em campos tão elementares, que atuam na estrutura dos próprios pensamentos ou nos argumentos que os sustentam. Talvez para que se possa melhor explanar sobre isso, convém remeter ao subtítulo referido a sua filosofia: "uma filosofia 
a marteladas". O sentido de esculpir, e não de destruir, permite, assim, através dessas formas, novas construções.

Contrariamente então ao que se pensa, diante de críticas tão avassaladoras que faz em campo da filosofia e a muitos filósofos, a obra de Nietzsche enaltece a vida, tornando-a vibrante em seu leitor, ou ao menos muito mais questionada e percebida, dada a valorização do seu próprio olhar, exercitado quase nitidamente junto com seu autor. Mais exemplos poderão ser dados ao longo deste texto.

Vale situar a obra nietzschiana em três períodos: o primeiro de 1870 a 1876 , o segundo de 1876 a 1882 e o terceiro de 1882 a 1888, considerado este último o mais avassalador em termos de críticas ao mundo moderno bem como a época de escrita da obra Assim falou Zaratustra - um livro para todos e para ninguém, (NIETZSCHE, 2011) já que, aqui, se irá trabalhar a denominação "super-homem”, presente de forma significativa neste livro.

Paralelamente a ele, o artigo de Rubens Alves, "O homem transbordante", será analisado em especial na qualificação "transbordante", expressão vista talvez de forma pretensiosa neste estudo, por paralelos que o radical "trans" permite estabelecer com outras ideias.

Rubens Alves, em seu artigo, diz que as palavras de Nietzsche não são para a cabeça, mas para as entranhas: "Eu o sinto circulando no meu corpo. E eu sei que isso é assim porque, ao lê-lo, ponho-me a sorrir, sou possuído pela alegria, viro criança. O que está muito de acordo com as suas intenções.” (ALVES, 2000).

Mas por que a importância de ser envolvido corporalmente por uma leitura, pensamento ou reflexão? Por que sair da teoria para a vivência, para a prática, para a sensorialidade (e como isso seria possível?!)? Muito provavelmente por sermos também, e sobretudo, sensoriais, e esta, por si só, ser razão suficiente a ser considerada. Vale dizer, a importância não somente do conceito, da teoria, do discurso, mas também da vivência, experiência e, por que não, da sensibilidade? E Nietszche é o artista desta sensorialidade filosófica, já que, como Rubens Alves bem escreve, pulsa e faz pulsar, nas entranhas e também com sorrisos.

Enquanto filósofo alemão do século XIX, Nietzsche rompe parâmetros e inaugura um próprio, o seu. E convida o leitor a fazer o mesmo. Sua forma pode ser dita nietzschiana e, com ela, critica grande parte do pensamento não só filosófico, mas especialmente as respectivas formas de filosofar. Impulsiona o diálogo interno tão frequentemente através de suas palavras, que parece mais um criador, um artista, um poeta. Mas sempre embasado por uma lucidez gritante, sendo ilustrado através de Fernando Pessoa por Rubens Alves em seu artigo: "Tenho 


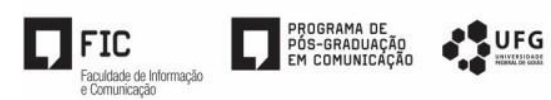

a lucidez de quem está para morrer.”, por provocar geralmente movimentos para lugares pouco ou nunca antes visitados. Assim, é um conforto para quem já se aproximou de algumas de suas ideias de forma solitária, e estimulante para quem adentra suas beiradas e águas pela primeira vez.

Rubens Alves traduz a expressão übermensch de Nietzsche como o "homem transbordante", indicando ser o radical "trans" mais adequado para o pensamento ativador deste filósofo-poeta ou artista-filósofo. Cita Willian Blake como se fosse o Nietzsche inglês (ALVES, 2000): “As cisternas contêm, as fontes transbordam.”. Para Alves, Nietzsche era tanto, que podia doar em seu transbordamento. Talvez até fosse melhor dizer que ele conseguia transpassar ou gerar esse trânsito do pensar para o sentir, do entendimento para o questionamento, do aceitar para o duvidar, do conhecer para o desconhecer, do conforto para o desconforto e tantos outros trânsitos de percursos surpreendentes ocorridos também em suas releituras. Uma escrita que aparentemente flui traz toda uma densidade orientadora, capaz de ser penetrada a cada novo momento. E a ponte aqui referida ao radical "trans", da colocação "transbordante" dada por Rubem Alves, também poderia ser relacionada ao transdisciplinar, já que seus pensamentos fazem esse movimento, percorrendo campos internos e mais facilmente tidos como desconectados, como razão e prática ou emoção.

Também faz pontos com outras tantas disciplinas, para as quais oferece bases de desenvolvimento, como é o caso das Artes, mas também da Administração, posto que o trabalho de seu pensamento atualiza não só novos como autênticos pensares, expandindo a própria ideia de abertura em nossas mentes. Ele aceita e trabalha o que poderia ser considerado à margem ou oposto, e faz relações apolíneas e dionisíacas necessárias e fortuitas, dialogando ao mesmo tempo com o infinito e com os limites.

De fato, o próprio Nietzsche transborda, por ser capaz de oferecer esse "trans", para além ou "a mais". Trabalha ele próprio o "homem transbordante" e, na tradução literal de über como "acima de", übermensch: "acima do homem”, jornada indicada para esse próprio homem, a ser transpassado. Nietzsche, então, não só apresenta capacidade de transbordamento, como, através dela, fala sobre a necessidade de um "super-homem", de um homem mais homem, superior ou acima dele mesmo: "Eu vos ensino o super-homem. O homem é algo que deve ser superado. Que fizestes para superá-lo?” (NIETZSCHE, 2011, p. 13).

Mas tal indicação de necessidade de superação poderia ser entendida antes como necessidade de mutação e, como toda mutação, não será tarefa fácil. O "acima do homem" 
exige-lhe uma metamorfose, e abandono. Morte de um homem que dê lugar a outro, e isso por meio de seu próprio desprezo e abandono de si (como cuidado de si?).

Vede, eu vos ensino o super-homem: ele é este oceano, nele pode afundar o vosso grande desprezo. Qual é a maior coisa que podeis experimentar? É a hora do grande desprezo. A hora em que também vossa felicidade se converte em nojo para vós, assim como vossa razão e vossa virtude. (NIETZSCHE, 2011, p. 14-15).

Há em Nietzsche indicação de agudas carências no homem, como se lhe faltasse um grande percurso, bem como incentivos e estruturas. Diante delas, transformações de diversos níveis são requeridas, a saber: "Onde está o raio que venha lamber-vos com sua língua? Onde está a loucura com que deveríeis ser vacinados? Vede, eu vou ensino o super-homem: ele é esse raio, ele é essa loucura." (NIETZSCHE, 2011, p. 15).

Nietzsche surpreende ao dizer tanto do homem como do "super-homem", como se esta própria possibilidade "de e para ambos" contivesse suas respectivas pontes (e quedas). Em suas palavras (2001, p. 16), “Grande, no homem, é ser ele uma ponte e não um objetivo: o que pode ser amado, no homem, é ser ele uma passagem e um declínio."

As críticas se direcionam à cegante luz provinda da excessiva valorização do pensamento considerado racional, eleito como orientador supremo dos caminhos, devendo portanto surgir outro tipo de homem, capaz de desbravar a si e para além de si, mesmo que, para tanto, lhe fosse exigido um caminho que ultrapassasse o esforço pessoal, talvez nem dependendo dele somente.

Esse aceno vem de Nietzsche numa época de supostas e eleitas conquistas que, por sua vez, eram demasiadas em auto-convencimento. $\mathrm{O}$ pensador alemão encoraja revolucionariamente o homem a enxergar sua atualidade limitada, devendo tal declínio ser buscado na direção de um saber desprezar a si, pois o perigo estava (ainda está?) neste acertameto que se pensa ou se sente referente e, por isso, faltante com a vida, não lhe correspondendo em movimentos, impulsos criativos e danças. Com ele é possível (sor)rir.

Que é amor? Que é criação? Que é anseio? Que é estrela? - assim pergunta o último homem, e pisca o olho. A terra se tornou pequena, então, e nela saltita o último homem, que tudo apequena. Sua espécie é inextinguível como o pulgão; o último homem é o que tem vida mais longa. "Nós inventamos a felicidade" - dizem os últimos homens, e piscam o olho. (NIETZSCHE, 2011, p. 16).

Sobre a necessidade de mutação, já mencionada, as parentes metamorfoses são apontadas por Zaratustra ao espírito: "Três metamorfoses do espírito menciono para vós: de 
como o espírito se torna camelo, o camelo se torna leão e o leão, por fim criança.”. (NIETZSCHE, 2011, p. 27).

Contudo, vale discorrer novamente sobre a tradução recorrente e frequente em termos de aparição, do termo superação. O homem, para Nietzsche, se apresenta como alguém a ser superado ou auto superado, embora a recorrência de ligação do termo über com superação ou autos superação possa apresentar algum desvio de tradução. "Super-homem", se houver estrita relação com über (acima de), talvez deva ir além da ligação com superação. Esse homem "acima", como em uma das traduções, bem como na colocação de Rubem Alves, transbordante, não se relaciona de forma garantida com o exercício de uma superação. Parece haver muito mais a ideia de mutação do que de superação buscada. E em uma mutação há ideia de morte, enquanto em superação existe mais a ideia de um agregar que leva a outro estágio. A leitura do livro, Assim falou Zaratustra, apesar de todo o conteúdo lúcido e orientativo, não oferece águas leves, fluentes. Podem ser águas, mas em muitos momentos elas são escuras, densas, pesadas, havendo fluência de lucidez, mas dificuldade de absorção, ou lentidão neste processo.

Talvez essa seja uma percepção isolada, mas supõe-se que muitas das acusações, feitas por Nietzsche em direção a esse próprio homem, nos atinja claramente enquanto espécie humana; através, porém, de amarga compreensão, alcança-se uma outra ainda mais fidedigna. Isso para se considerar a necessidade de absorção de muitos conteúdos profundos e ácidos, como a ideia de um homem que deve morrer para dar lugar a um outro, super, acima. Não necessariamente superado, mas extinto, transmutado. E, quanto ao sentido "transbordante", dado por Rubem Alves, expande muito mais o pensador Nietzsche, considerado como capaz, sim, de superar qualquer outra forma de pensamento na filosofia, sendo um revolucionário, um marco em sua história, assim como "trans", já apontado, não só por atravessar em sua proposta formas de pensar e de considerar, únicas, como por ir além dele próprio na forma peculiar de sua escrita e pensamentos desbravadores no cenário do pensamento filosófico.

E como ficamos então, já que a relação entre homem transbordante e o termo transpessoal, ainda a ser explanado no capítulo seguinte, apresenta as ressalvas importantes, citadas acima, a de que a tradução de übermensch se relacionou de forma talvez equivocada com a palavra superação/ autossuperação? Ainda se deve dizer da ideia de transbordamento como capacidade de doar, jorrar para fora, já que se pode transbordar em termos humanos.

De uma forma ou de outra, o radical "trans" se faz presente. De forma ainda mais marcante, pois seu próprio criador, possivelmente até mesmo por conseguir atualizar em si essa condição, honre-a e se relacione com ela. E também porque o "super-homem" nietzschiano, em 


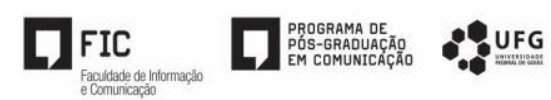

sua mutação norteada (e necessária, na visão do autor), deva passar por uma superação tão intensa que possa ser chamada de transmutação, indo além de uma simples superação, se é que seja possível dizer assim. E será possível esse acontecimento? Ou apenas elucidado como premente na condição humana? Parece haver uma exigência de transformação, na ordem de transmutação, que pode ser englobada, mas necessariamente transpassada, ou ainda, ultrapassada (ela mesma superada). Como será a possibilidade de participação ou de relação da perspectiva transpessoal com este "evento"?

Talvez Nietzsche deixe clara essa falta inaudita no homem para ele mesmo, mas enquanto pensador e filósofo homem, através de seu apontamento, já possibilita um caminho. Enquanto a perspectiva transpessoal reforça em direção oposta, como se houvesse essa capacidade de ir além, mas contemplando esse homem sempre. É o que também Nietzsche faz, mas de forma tão grave em termos de faltas, distâncias deste homem para um possível (ou difícil) "super-homem", havendo aí o forte estabelecimento de que o homem precisa ser ou aproximar-se de um outro homem, que esse homem apenas não basta, é-lhe necessário morrer para si mesmo, ou para este. Esta parece ser a grande importância desta obra de Nietzsche para este trabalho: a de que a condição humana, de apenas homem, não basta.

Assim, apesar dos cuidados com a palavra übermensch, associada a "super-homem", e este superpoder ser sutil e significativamente diferente de superação, fica clara a complexidade da natureza humana, de suas faltas, bem como e igualmente de suas possibilidades ou, ainda melhor, necessidades de possibilidades para poder ser mais integral. Porém, parece que a ideia de integralidade não foi trabalhada por Nietzsche, pois antes de ser possível essa visão, haveria a necessidade de integração. Ou talvez a integração se daria pelos estados de transmutação apontados, do camelo, do leão e da criança, pressupondo abandono do anterior, tornando-se outro ser. Sua preocupação estaria em deflagrar que só a condição de homem (tal como apontado por ele) não seria suficiente, e seria até mesmo uma aberração.

Daí sua orientação apresentar como caminho, não conhecido ou trilhado, a transmutação, ou ainda remetendo à dialética hegeliana, que diz que a flor veio da semente, mas que elas são tão distintas que há a morte de uma para outra. Há que considerar que a época de Nietzsche foi a mesma de Freud, logo, visões menos integradoras parecem não receber o melhor contexto nesta época, podendo até ser colocada em paralelo essa visão radical ou mais perspectivista do homem apresentada em uma época que devia precisar desse descortinamento: a de que temos, pela ótica freudiana, inconsciência, pulsões não controladas, e uma natureza humana muito pouco humana, neste homem carente em sua necessidade de metamorfose, para 
atingir a instância "super". Logo, há muito a ser trabalhado, feito, trilhado, acontecido. E talvez o mais importante expresso por Nietzsche tenha sido: o quanto a falta deste mesmo homem deva ser desprezada. Mas se espera também que, através dele mesmo, quando atinge seu pósabismo, pela (trans)mutação alcance outra condição, bem como necessidade: a de um superhomem. Cabe a pergunta: há algo que esse homem possa fazer para tanto?

$\mathrm{Na}$ visão nietzschiana, há a deflagração de uma condição intensa de carência. Mas através da própria deflagração ele inspira esta possibilidade e torna-se (ou se aproxima desta condição) super-homem na história da filosofia, pois revoluciona não só o pensar como a sua forma aforística e concentrada em lucidez. Seu pensamento marca uma época já receptiva às visões inauguradoras de outras, como foi a introdução da sexualidade infantil por Freud numa sociedade que não se relacionava e nem tinha abertura para tal concepção. Nietzsche produz esse "tranco" no pensamento filosófico e histórico, enquanto Freud introduz olhares e considerações nunca antes sequer suposto. Karl Marx (1818-1883) também revoluciona o mundo com o seu pensamento sobre a transformação social, fazendo e modificando a história, como se observa em sua frase proferida: "Os filósofos se limitaram a interpretar o mundo. Cabelhes agora transformá-lo.". Época de grandes questionamentos e introdução de inéditas visões, sendo sinalizada já a necessidade desse "trans", para além.

Nietzsche influencia sensivelmente as Artes, até os dias de hoje, pois é possível que, na época em que viveu, as faltas para o homem, mesmo que não apontadas como próprias de uma época, mas de uma natureza humana, pudessem ter mais necessidade de serem conhecidas ou expostas. De qualquer modo, parecia haver uma urgência em proclamar a pequenez do homem, bem como sinalizar esse salto transmutador e, para tanto, orientá-lo, como também tornar nítida esta sua própria falta. Nem é preciso dizer do termo utilizado pela primeira vez por Jung, überpersonlich (MACIEIRA, 2015, p. 4), como sinônimo do inconsciente coletivo, reforçando essa transformação de referências que passaram a influenciar o mundo sobremaneira até os dias atuais.

Tal homem, super ou acima, vai além de uma superação, posto que sofre uma mutação. De qualquer forma, para ser alcançado este caminho, sempre haverá a necessidade de ir além de si mesmo. A proposta deste trabalho envolve a perspectiva transpessoal. Como ela se relacionará com este processo do homem para além dele mesmo?

A proposta deste trabalho foi relacionar o pensamento de Nietzsche, especialmente no que diz respeito ao denominado "super-homem", com a abordagem da transpessoal. Houve ressalvas feitas em direção à expressão usada por Rubem Alves com relação à tradução de 
übermensch, "homem transbordante", sendo talvez tal definição muito mais apropriada ao próprio pensamento de Nietzsche, enquanto alcance gerado para sua época, bem como inspiração até os dias atuais. Retoma-se o assunto porque o termo alemão über, literalmente significando "acima", foi traduzido como "superação", e na leitura da obra Assim falou Zaratustra há reconhecimento da necessidade de uma intensa superação que poderia ser melhor denominada por mutação ou, ainda, metamorfose, como se houvesse uma morte de algo em prol de outro. Mas, mesmo diante de uma ideia de superação ou de metamorfose, mutação e morte propriamente ditas, o ser humano tem de acessar novos estágios, e a questão que se põe é: a perspectiva transpessoal poderia ajudar nessa empreitada? E será que ganharia também com o pensamento de Nietzsche e sua defesa de um "super-homem"?

Para Nietzsche, "O homem é corda, atada entre o animal e o super-homem - uma corda sobre um abismo." (NIETZSCHE, 2011, p. 16). Se houver consideração dessa como sendo uma espécie de miséria humana, quando se dá conta de que tal abismo participa, está no homem e é como se lhe negasse a própria vida ou existência, ou ainda, como se lhe imprimisse uma condição de urgência ou conhecimento de que parte dele não está presente nele ou, ao mesmo tempo, que essa "falta" pode lhe servir de referência, como um membro amputado que persiste em ser "sentido", tal abismo então em si participa deste ser homem, por isso a necessidade de saber-se do outro lado dele, ter essa orientação (há essa orientação mesmo enquanto abismo), como se pudesse ser atingido por esse outro homem. Há um abismo que separa e compõe por meio desta forma. Seria essa imagem, apresentada por Nietzsche, considerada atemporal ou talvez necessária a uma época ensimesmada e, por isso mesmo, merecedora de um apontamento mais radical deste mesmo homem? Não será de todo possível afirmar isso, pois tal época não é mais a mesma, e mesmo Nietzsche, sendo intensamente estudado não só no campo da Filosofia, oferece-nos sua própria subjetividade e perspectivas pessoais. É filósofo, pensador, mas não deixa de ser homem, ser humano, e apresentar sua própria dimensão subjetiva não acessível. Mesmo assim, como saber se seu apontamento pode ser considerado atemporal ou pertinente em um momento de carência desta informação? As duas considerações serão aqui acolhidas.

A ideia do próprio homem ser uma corda em um abismo e estar nesta condição suspensa, a de ponte entre o animal e o super-homem, torna-o muito pouco integrado, ou seja, torna-o brutalmente formado, ou ao menos apontando para a ideia de disjunção, de condição ímpar, através desta tríade. A percepção da condição possibilita o reconhecimento do abismo. Mas como traduzi-lo melhor? Há metáforas possíveis para esse abismo (no/do homem)? Trabalhar intimamente a pertinência desse contexto apresenta o desafio, mas em relação à atualidade tem- 


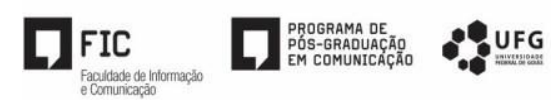

se mais estímulo para a desconexão com o presente, ou com os chamados estados presentes. A velocidade com que é possível realizar algumas tarefas, bem como acessar alguns dados, não se compara com outra na história. Porém há apenas uma ilusão de conhecimento diante de tanta informação possível de ser acessada. E sabe-se também que uma informação não representa necessariamente conhecimento, muito menos sabedoria, já que, muitas vezes, não há, contraditoriamente, relacionamento com o próprio tempo. Nesse sentido, mesmo sabendo da limitação dos sentidos, é através deles que acessamos o pensamento, mas o excesso de estímulo acaba por assim, por anestesiá-los, contrariamente ao que seria ideal ou desejável. E aí inaugura-se uma de nossas misérias: a desconexão com nosso próprio presente e presença. Desse jeito, conseguir manter-se presente ou em estado presente pode gerar uma mutação na vida de quem consegue vivenciar tal experiência, pois aniquila o estado de não presença e cria, simultaneamente, uma intensa e silenciosa transformação para o mundo, pois não haverá resposta para a velocidade ilusoriamente produtiva. Assim, uma resposta a esse abismo seria a já referida mutação, salto capaz de oferecer alívio para um homem suspenso. Mas será que podemos chamar apenas de alívio a sensação obtida em situação tão complexa?

Ao que parece, esta atitude simples, mas não necessariamente fácil, seria capaz de gerar uma transformação radical, dentro e fora. Meditar, praticar ou exercitar a presença, se é que seja possível falar assim, opera milagres, metamorfoses em nós e para além de nós. Por quê? Por sermos no tempo, com ele, junto dele, percebendo-o e deixando-o passar, mas em íntima conexão. Ele nos faz, mas nós não necessariamente o fazemos, apenas somos através dele, de várias formas: de formas descoladas dele próprio, quando não nos percebemos junto, em linha com ele, quando adentramos o automático ou não percebemos a ação. Mas quando seguimos em um mesmo compasso, a vida pode ser vibrante e vivida em estado desperto, mais consciente, de forma sintônica.

Como entender melhor a expressão "em linha com o tempo"? Parece haver uma necessidade de atualização do homem para com ele próprio. Usando a linguagem da informática: uma atualização de software. Porém, uma de um tipo que lhe é original de fábrica, de primeira versão e, apesar de primeira, a melhor, mais capaz e mais evoluída. Neste ponto, podemos pensar que há um trabalho do homem de reconhecer em si uma, ou a sua fonte sempre fonte, e que essa atualização seja através do próprio reconhecimento. Grande desafio em um mundo que apresenta e fortalece a ideia contrária, e que acaba por distanciar a visão e sensação desta fonte. Mas na imagem apresentada por Nietzsche, o animal é parte desta fonte. E há possíveis considerações acerca de um animal, mas que sempre leva à ideia de predominância 
do instinto ou da reatividade em prol da sobrevivência. Como tratar essa parte como fonte? Sim, nesta fonte há uma herança, bagagem, ponto de partida a ser considerado, trabalhado e possível de se atualizar pela perspectiva transpessoal. Como este animal pode ser melhor acolhido por nós mesmos? Ele precisa ou não de acolhimento? Como aproximá-lo de nós mesmos? Há algo de melhoria nesta aproximação? Seria necessário ver, trabalhar, averiguar, de forma vivencial, os princípios desta perspectiva, que enxerga o ser humano sob várias perspectivas e confere extrema importância à vivência, prática e percepção experiencial. Haveria alguma sabedoria neste instinto? De que espécie?

A Perspectiva transpessoal agrega novas perspectivas e questões referentes ao ser humano, como a dimensão espiritual participante da psique. Pode-se pensar em colher, ou se propor fazê-lo, quando diante do âmbito animal e homem, com referências possíveis a um "super-homem". Trata-se do mistério do três, da trindade, pois o um ou uno existe apenas conceitual ou filosoficamente. $\mathrm{O}$ um pressupõe já o três: o um e o não um gera relação entre eles. O um animal e o três super-homem pressupõem-se a relação dois, o homem. Daí a importância da pessoa e do para além dela, do transpessoal. Mas ressalta-se que, neste caso, tal pessoa também se pode dizer pessoa-animal e além-pessoa. Muito além, daí o radical super. Como fazer uma relação do significado de "trans", que está na perspectiva transpessoal, com o “super-homem"? São sinônimos? Convém lembrar os muitos caminhos que podem levar à ideia de um ou uno. A proposta nietzschiana envolve um tipo de morte através da pressuposta necessidade de mutação. Na abordagem da perspectiva transpessoal isso pode ser feito não necessariamente sem dor, mas pode não envolver uma mudança que se caracterize por morte ou metamorfose. Pode até ser assim também, mas há mudanças mais sutis, não menos poderosas, quando se reconhece ainda muito de suas partes. A imagem de Nietzsche, nitidamente, apresenta muita força, radicalidade e intensidade para esse próprio homem sobre ele mesmo. E, como já apontado, imagem talvez necessária para uma época adormecida em relação à complexidade deste mundo. Nesse sentido também, o termo complexidade pode ser adequado para este homem tanto na construção nietzschiana, como na visão da perspectiva transpessoal. E se a Psicanálise freudiana igualmente pode ser considerada em condições de diálogo com o pensamento complexo, o princípio fundamental que a torna menos comunicadora, ou até menos complexa, seria sua abstenção em considerar outras instâncias externas que lhe escapam, ou que por ela não sejam assim denominadas, mas, uma vez não reconhecidas, não podem ser legitimadas, como se a Psicanálise permanecesse hoje em um campo fechado. Há grande importância em reconhecer um movimento, uma característica, um 
âmbito, dentre tantas outras necessidades, daí a mais que pertinente abertura, a consideração da amplidão (considerare, do grego, estar com o céu). O reconhecimento pode ser uma forma de existência. A perspectiva transpessoal tem a pré-disposição para reconhecer outras visões, diante de sua abertura, em termos de propostas e práticas. Por isso, ante a ideia de homem nietzschiano - que aparece como figura misteriosa entre inícios e fins tão distintos como animal e além-homem -, apresenta a amplitude de sermos muitos, e não facilmente se dá conta disso, da integralidade existencial. Cabe, contudo, um trabalho desta abordagem psicológica diante da multi, pluri e transcondição humana. As configurações apresentadas - animal, homem, "superhomem" ou pessoal, transpessoal - são distintas, mas passíveis de significativas trocas, pois também somos compostos de abismos, e para uma relação com eles precisamos igualmente da recepção, acima citada, pois, mesmo proposta a integração, deve ser considerado o mistério. Cabe supor que o abismo em nós pode causar abismos no mundo, entre as áreas, ou seja, podemos refletir este(s) abimo(s), daí o saudável questionamento, mas também a abertura para fazer relações, pois o mistério nos é comum. Nas palavras de quem foi o Pai desse pensamento:

É importante que tenhamos um segredo e a intuição de algo incognoscível. Esse mistério dá à vida um tom impessoal e "numinoso". Quem não teve uma experiência desse tipo perdeu algo de importante. $\mathrm{O}$ homem deve sentir que vive num mundo misterioso sob certos aspectos, onde ocorrem coisas inauditas - que permanecem inexplicáveis - e não somente coisas que se desenvolvem no limite do esperado. O inesperado e o inabitual fazem parte do mundo. Só então a vida é completa. (JUNG, 1963, p. 308).

A falta, a ausência, eis outras possibilidades de leitura para esse abismo. Uma possível miséria da configuração humana. Interessante notar que o radical miser ou miseris está também na palavra misericórdia, que significa "dar o coração àqueles que são vítimas da miséria". Configura-se a falta e, ao mesmo tempo, a necessidade de "misericórdia" em relação a ela. Diante desta constatação, afere-se que tanto o humano como sua humanidade são requisitados, e também o que está para além deles. Assim sendo, transitar se faz preciso, bem como a existência de um caminho. E, neste trânsito e percurso, a perspectiva transpessoal oferece condições de estrada - orientação, segurança e acesso -, pois reconhece que esta viagem pode trazer uma nova consciência, capaz de ir além dela mesma, de forma plural, sendo possivelmente esta a sua condição.

A partir daí, sim, a perspectiva transpessoal, com suas disposições de abertura e também de integração, atua com capacidade de oferta de rotas, caminhos, sensorialmente sinalizados e percebidos, mas também com paradas nestes mesmos caminhos para apresentação de novas e 
possíveis rotas dentro deles, as quais por sua vez, integram ou ao menos oferecem mais de uma realidade ou possibilidade de sua vivência, em um mesmo caminho, por meio de outros. Esta seria sua capacidade, a capacidade do "e", da coexistência: pessoa e trans-pessoa, caminho e caminhos. Dessa forma, sendo também integrativa.

\section{CONSIDERAÇÕES FINAIS}

A escolha do tema deste ensaio inspirou-se na abertura e integração presentes na quarta força da perspectiva transpessoal. E diante de tais predisposições, considerou-se o pensamento filosófico de Nietzsche no livro Assim falou Zaratustra, obra do terceiro período do autor, considerado o mais crítico ao mundo moderno

Constatou-se identificação de pressupostos distintos na visão do homem/ "superhomem", da obra nietzschiana, e pessoa/ trans-pessoa, da perspectiva transpessoal. Porém, os possíveis ganhos foram em direção à ideia de que ora será preciso morrer, ora transbordar. E, em ambas as ideias, é possível trabalhar a noção de abertura, como a de integração. Resta saber se, na prática, será possível integrar algumas partes, mas, mesmo assim, na proposta nietzschiana de morte ou mutação do homem para o super-homem, pode-se investigar sobre a possibilidade de uma integração às avessas, ou diferenciada, que leva a um outro estado, por sua vez incansavelmente buscado e trabalhado pela perspectiva transpessoal. Talvez essa perspectiva não se preocupe tanto em saber o quanto deste ser "antigo" (homem, como exemplo) está presente no ser novo ou (re)integrado ("super-homem”). Mesmo se distintos, a perspectiva transpessoal já caminha para além deste paradigma, ou seja, sabe existir uma outra condição, chamada também de outro ou outros estados de consciência.

Então, enquanto na obra de Nietzsche havia a importância de apresentar algumas faltas, condições e possibilidades humanas, para a perspectiva transpessoal em geral cabe trabalhá-las, relacionando-se com elas. Mas cabe a pergunta: por que a perspectiva transpessoal se relaciona não só conceitualmente com essa imagem de homem nietzschiano? Por aceitar outros estados de consciência, estados estes que nos escapam por sofrerem interferências não apenas do inconsciente pessoal, o qual tudo perpassa, porém, se há outras instâncias e aceitação de uma dimensão espiritual inteligente e partícipe da própria psique, como saber então se será possível outro ser humano, ou consciência, para além deste próprio homem? No caso, resta saber como não será. 
Em Nietzsche, a ideia de mutação refere-se a quanto há para ser alcançado, e a perspectiva transpessoal atua em um campo aberto, mas tem os seus princípios respeitadores da pessoa. Por isso, entra em cena a importância do termo integração, sem o qual não seria possível segurança no processo, como também não seria possível, apresentar a hipótese de que uma integração não necessariamente embute a ideia de harmonia, direcionando-se mais para conscientizações de variados níveis ou tipos, adquiridos no próprio percurso exercitado pela perspectiva transpessoal

Sendo assim, o chamado "super-homem" pode não ser integrado ao homem, como a pessoa idealmente seria à trans-pessoa, mas o delimita como estado ou ser possível. Concluiuse assim que tanto a perspectiva transpessoal, como a visão de homem nietzschiana, apresentada neste livro, levam à necessidade desses vários homens (ou estados de consciência), sendo vivenciados estados variados, como o de morte, mutação ou transbordamento.

Vale ressaltar a ideia de movimento por nós mesmos, mas mais importante do que ela seria a capacidade de vivência e sensorialidade fortalecidas pela prática da perspectiva transpessoal e também na escrita filosófica nietzschiana, que, através de seu próprio transbordamento, apresenta possibilidades de e para nós tão desconhecidas e, por isso mesmo, passíveis de alcance ou consideração.

\section{REFERÊNCIAS}

ALVES, R. O "homem transbordante”. Folha de S. Paulo, São Paulo, 22 ago. 2000. Disponível em: <http://www1.folha.uol.com.br/fsp/opiniao/fz2208200009.htm> Acesso em: 7 out. 2018.

JUNG, C. G. Memórias, sonhos e reflexões. Tradução Dora Ferreira da Silva. Rio de Janeiro: Nova Fronteira, 1988. 361 p.

MACIEIRA, R. C. Conceitos, histórico e desenvolvimento. curso de psicologia integrativa transpessoal. São Paulo: Instituto Junguiano de Ensino e Pesquisa, 2015. 23 p. Notas de Aula.

NIETZSCHE, F. Assim falou Zaratustra - um livro para todos e para ninguém. Tradução Paulo César de Souza. São Paulo: Companhia das Letras, 2011. 359 p. 